\title{
URBAN STRUCTURE AND MOBILITY IN THE CONTEXT OF SUSTAINABLE DEVELOPMENT: CITIZENS' OPINION ABOUT THE THESSALONIKI SUBMERGED TUNNEL
}

\author{
I. FRANGOPOULOS ${ }^{1}$, N. DALAKIS ${ }^{2} \&$ D. KOURKOURIDIS ${ }^{2}$ \\ ${ }^{1}$ Department of Planning and Development, Aristotle University of Thessaloniki, Greece. \\ ${ }^{2}$ Department of Rural and Surveying Engineering, Aristotle University of Thessaloniki, Greece.
}

\begin{abstract}
In this paper, on the occasion of the decision to construct the Thessaloniki submerged tunnel (TST), we set the problem of the urban evolution of the city in correlation with mobility, through empirical investigation of the citizens' views. As theoretical tools we use strategic planning and urban governance in order to achieve modern planning proposals that presuppose processes of social transaction between social actors and other social partners (active social groups, agents, etc.) for the sustainable development of the city. Methodologically, we worked with 621 questionnaires, within the urban agglomeration of Thessaloniki, which were given out and collected between 7 and 9 March 2007. The statistical analysis of the sample was carried out using the SPSS software. Primarily, we examine the development of the city during the 19th and 20th century in relation to the Thessaloniki linear sprawl problem as well as the communication between the two city poles, the west and the east. We continue with the presentation of the social and spatial features of the sample as well as the major issue of the assessment of the traffic, environmental and urban impacts of the TST. Then, we examine the structure of the urban mobility. This is followed by an analysis of the issues with regard to the housing areas and the intention to use the TST, the reasons for commuting from the west to the east and vice versa, and the evaluation of the impacts according to the housing areas. We also verify the correlation of demographic variables such as sex and age with the use of routes such as the TST, central streets and ring road. Finally, we evaluate the impacts of the TST in terms of the association between the intention to use it and variables such as sex and age.

Keywords: participatory planning, questionnaire survey, strategic planning, sustainable development, Thessaloniki submerged tunnel, urban mobility, urban structure.
\end{abstract}

\section{INTRODUCTION}

The purpose of this research is to investigate and record the opinions of a representative sample of the citizens of Thessaloniki on the controversial project of the Thessaloniki submerged tunnel (TST) and its impact on the city. The project received both public and private funding and has raised a serious debate regarding its usefulness, its funding and its urban and environmental impact, especially on the new quay. Primarily, the project of the submerged tunnel is set in a theoretical background of strategic planning, participatory practice and evolution of modern metropolises, through theory and international actuality. Effective urban governance through the investigation of the citizens' opinion in relation to the sustainability of urban intervention of such a scale is important for us, as it can 'transform' the users into active participants of the sustainable development of the city. We believe that citizens' opinion constitutes a substantive part of urban planning and should be regarded as such during the decision-making process. We continue with the presentation of some historical facts on the evolution of Thessaloniki's urban fabric, combined with its linear, bipolar urban development and the traffic and communication problems of these two poles. The third part of our research refers to the identity of our sample, its social and spatial features, the facts about urban mobility and social representations for the city areas that emerge from the participants' answers, the assessments of the submerged tunnel's impact and the variations of attitudes and opinions based on the area of residence. Finally, by correlations of factors such as sex, age and intent of TST use, we make assumptions concerning 
the modern cultural patterns the residents adopt and the awareness of the transportation problems, through the search for alternative ways of city transportation.

\section{THEORY AND METHODOLOGY}

In the current international, economical, social and cultural environment, the cities are not closed and self-sufficient survival systems. The cities compete for the recruitment of capital and business by carrying out either economic or urban space improvement strategies. Urban policies transform into new models of urban governance that focus their efforts on the development of the cities through the quality of urban space [1]. Strategic planning, as a process, defining the long-term targets and strategies for their realization, includes the combination of public and private initiatives with the active participation of the involved population who will use the project and experience its impact. On a planning level, urban governance combines complex participatory processes with extensive, multiple intermediations between both private and public basic institutions [2]. Social transaction is a prerequisite for the effective management of social actors and other social partners (socially active agents, groups and individuals) [3]. The cities, as ventures of urban policy and governance, entail complex planning proposals with active engagement of a sociological and anthropological view of space [4]. The opening of the submerged tunnel is a very important project for the second largest city of a country that suffers the impact of globalization more and more. The stake of the opening of this tunnel poignantly portrays the need for a modern strategic planning for the development of Thessaloniki as a 'metropolis of the Balkans', through the connection of public and private initiative with participatory processes that guaranty sustainable development. The major conflicts that came up last year concerning this project depict the incapability to incorporate processes of social transaction between the institutions and the social groups of the city. This theoretical approach pertains to the logic of scheduling and planning which in the case of the submerged tunnel was not adhered to. Furthermore, if we raise the question of sustainable development combined with planning at the city level [5, 6], we find that the result of the objections and reactions raised by both active public groups (e.g. 'Citizens against TST' [7]) and academics specialized in urban planning [8] is positively correlated with the position of the citizens questioned in our sample. The critiques against the project emphasize the lack of its viability and refer, among other things, to the fact that it encourages mobility based on private means of transport instead of public transport, such as the metropolitan bus and subway, although the latter is still at the construction stage, and to the reduction of green space because of the widening of a part of the road above the sea level - a fact that will contribute toward a bigger cutting off of the urban fabric from its natural continuation, the sea. These positions are supported, as we will find out, by the replies of the citizens of Thessaloniki to questions about the environmental impacts of TST. Consequently, the question set at this point is whether strategic planning and urban governance should take into account the sustainable development, part or precondition of which is the acceptance, the support and the multiplying of the impacts of a specific and set kind of intervention in the urban space.

In parallel to the issue of the sustainability of the project, it was claimed that the submerged tunnel would help the completion of the ring road in the south part of the city, which until now was restricted by the natural obstacle of the Thermaikos Gulf. But, can the TST project, being a major road project, bypass the city center? There is an important debate here, and a serious counterargument is that it is meant for facilitation of traffic, localized to a relatively short bypass of the historical city center. We will only keep in mind the fact that in any case it is a road project that intends to facilitate urban mobility.

The sociological approach of the city and the international experience of the evolution of big cities in Europe and America are the approaches which show that the exponential urbanization of the past century brought new realities in the foreground. From the urban ecology of Park [9] and the organization of the 'natural areas' and districts in the cities to the suburbanization after World War II 
in the states, studies [10] show that the development of the suburbs led to a degradation of the inner city zones. Key point of the analysis is the discovery that transportation with privately owned vehicles was boosted and an extended network of road network was constructed. Later on, these two factors facilitated the transformation of these suburbs into cities. Of course, the central business district of the American city that is analyzed is different from the center of the French model city, which has less functional aspects and more socially unifying aspects [11]. It is now unquestionable that the tendencies of metropolization and urban diffusion are closely connected to the boom of mobility and the emergence of new places of activity [12]. The issue of Thessaloniki's development does not differ from the above processes and it seems to connect the American and the European model of city development that is diffused but insists on the importance of the traditional city center.

In this context, the development of governance mechanisms at a metropolitan regional level exceeds the narrow boundaries of the city and it includes complete functional spatial entities. These entities form the basis of the measure that mainly refers to the daily commuting zone [13]. These are the exact forms of governance that are missing from the planning of the major urban intervention, the TST. This absence of strategic planning is mirrored in the opinions of the citizens of Thessaloniki.

This research - even if it comes in the aftermath, as the final decisions for the realization of the project have already been made - gives voice to the citizens so that they could express their opinion on this important urban intervention. Therefore, the methodology of this research was based on the questionnaire for acquiring data, which was addressed to citizens (over 15 years old) who reside in the wider urban agglomeration of Thessaloniki. In order to put the questionnaire together, we conducted a series of semi-directed and structured interviews with (a) experts, (b) 'privileged witnesses' and (c) a sample of the involved population, so that the final form of the questionnaire would avoid influencing the person questioned and would pose the questions in as neutral a manner as possible.

The sample of the research was selected randomly, but an effort was made to make it as representative as possible, as it is calculated to a great extent in reference to sex, age, educational level and residency. The areas were not selected in accordance with the administrative division of the municipalities of the urban agglomeration of Thessaloniki, but by consideration of the way the citizens define the city center, the western or eastern districts and the suburbs. The research was conducted from 7 to 9 March 2007, with the participation of 621 citizens. During this period, there was no intense public debate, no interventions or statements in the mass media on the subject of the submerged tunnel that might influence the participants' answers. Finally, both the primary analysis of the questionnaires and the verification of the variables were carried out using the SPSS software.

\section{DEVELOPMENT AND EVOLUTION OF THE CITY OF THESSALONIKI: THE URBAN DIPOLE AND THE BYPASS OF THE CITY CENTER VIA THE SEA}

There are three prevailing periods of evolution of the city's urban fabric in recent years (19th and 20 th centuries). An inherent phenomenon that obeys geomorphologic parameters (a narrow passage between mountain and sea) and involves urban interventions (demolishing of the Byzantine walls 1866-1889, redesigning after the 1917 fire) is the emergence of a unified urban center which 'pushes' the city's future expansion to the east and west.

As for the three periods, we define the first as the emergence of a center that puts forward rationalist functionality [14] as opposed to the self-contained, small, scattered and introverted neighborhoods of the Ottoman years. In the second period, we notice the phenomenon of population increase caused by the incoming of refugees (1922-1928) and the post-war population boom (1951-1971) due to inner migration and agricultural exit. The third period refers to the new inflows of native population and economic immigrants from the Eastern European countries, and it is shaped by the phenomenon of suburbanization and the emergence of a new middle class. 
So, a new compact center emerges, defined by the city block and the design based on the hippodamian system which unifies the city but marks its transferability from east to west via five basic road axes. Successive expansions of the city to the east and the west (agricultural rehabilitation for refugees of the 1922 Near East Crisis, ex. Kalamaria, Polihni), illegal constructions and the unauthorized urban expansions resulted in the augmentation of the eastern and western parts of the city and in the impressive phenomenon of the incapability to empower the city center, not as a symbolic and administrative element anymore but as a unifying access point from all sides of the city.

Thessaloniki with its one million inhabitants is a city which has seen its size more than double itself within a period of 40 years. The complete urbanized area of Thessaloniki's urban agglomeration is 5.500 hectares, a basically compact area with high density and intense clustering problems. Additionally, the main characteristic of the modern urban development of Thessaloniki is the intense reconstruction in the zone around the city, both in the urbanized parts and in the ones that are outside the city plan. In general, the intense diffusion of houses and almost all economic activity in the space around the city is one of the basic characteristics of its structure, with consequences on the urban flows and the quality of the environment and on the capability to manage these consequences [16].

Given the location of the central and historical area of the urban fabric of the city between the 'natural boundaries', the mountain in the north and the sea in the south, the city did not have the option of expanding in the north-south axis. Consequently, the urbanized space expanded in the east-west axis and in the perimeter of the Thermaikos Bay. The existing housing development shows a city shaped with its center being the point where two interconnected circles are joined, covering an area larger than the current limits of the urban agglomeration of Thessaloniki (Fig. 1). So, the two urban poles (eastern and western) communicate through five basic road axes that pass through the center of the city.

Additionally, the current condition of Thessaloniki's transportation system - with the rapid expansion of the city and its activities, the great rise of the vehicle owning index and the constantly rising need for transportation, combined with the absence of new projects, the deficient or bad management of the existing infrastructure and the absence of urban transportation policies [16] - demanded the circumvention of the center and at the same time the connection of the urban dipole with the construction of the Inner Ring Road (late 1980s) and then the Outer Ring Road. The completion of the ring road of the urban agglomeration of Thessaloniki requires bypassing the center via the sea. At present, the project of the submerged tunnel that is under construction attempts to solve this problem in a localized manner.

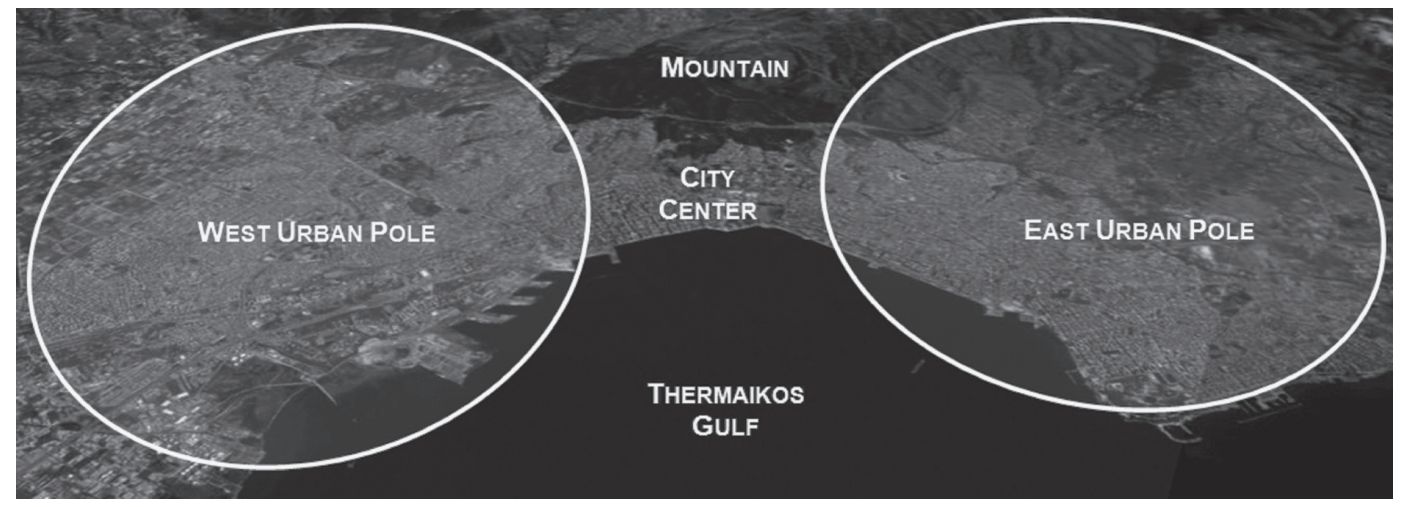

Figure 1: Thessaloniki's city center as the contact point of two urban poles. Source: Google Earth, authors' elaboration. 


\section{THE EMPIRICAL RESEARCH}

\subsection{Social-spatial characteristics of the sample}

As far as demographics go, the research sample includes 284 men (45.7\%) and 337 women (54.3\%), of whom $22.4 \%$ are 15-23 years old, 25.2\% are 24-29 years old, 33.3\% are 45-64 years old and $0.5 \%$ are $\geq 65$ years old. The educational level of the participants is rather high, the largest percentage (30.9\%) being high school graduates and $29.6 \%$ being college graduates. It is also worth mentioning that a large part of the sample (12.4\%) has a postgraduate or doctorate degree and only a small part $(5 \%)$ has not finished high school. As for the residency of the participants, the largest part (34\%) resides in the eastern districts, followed by western districts (29\%), the center of the city (23.5\%) and the eastern and western suburbs (7\%). As for employment, the vast majority of the sample is employed (78.3\%) and the $21.7 \%$ who do not work are mainly high school students and college students and those who are unemployed, as can be concluded from the age span of the sample, because the percentage of the sample in the age group of $\geq 65$ years is very small. The basic work areas of the sample are the city center and the western districts, with about $30 \%$ each, followed by the eastern districts with $18.7 \%$.

\subsection{Urban mobility and representations for the city areas}

Next, we attempt to record the daily transportation habits of the participants and, indirectly, the representations they have for the center and the other parts of the city. The participants use mainly a privately owned vehicle $(46.1 \%)$ and the buses $(32.1 \%)$ for their daily transportation needs. Another important part of the sample (11.8\%) travels daily on foot. As for visiting (and passing through) the center, $32 \%$ of the participants pass through or visit the center daily, $40 \%$ one to three times a week, while $28.4 \%$ less than once a week. Recreation-entertainment $(28.2 \%)$ and work $(25.7 \%)$ are the main reasons of these transports. As for passing through the city on the east-west axis or vice versa, the vast majority of the sample (72.5\%) uses this option, which proves that there is an intense spatial mobility. These transportations are mostly made for business $(34.7 \%)$ and recreation-entertainment (26.4) reasons. For this transport, 56.7\% of the participants choose the inner streets network of the city, while $43.3 \%$ choose the ring road. This confirms that although the tendency to bypass the city via the ring road is high, the transferability of the city is not appalling to the citizens - even under these conditions - and it may still have a symbolic attraction for the residents of the eastern and western areas.

\subsection{Opinions on the submerged tunnel and its impact}

After the investigation of the social and spatial characteristics of the sample comes a series of questions with the purpose of recording the participants' opinion on the submerged tunnel and its impact. In these questions, the tunnel was viewed as already existing, and the participants were asked to imagine how it would function in relation to the city's transportation system and their daily transports. To the question, which of the three roots - the main streets of the city, the ring road and the submerged tunnel - they would choose if they had to travel east or west, depending on the area of residency, the largest part of participants chose the ring road (46.4\%), another part chose the central streets of the city $(30.4 \%)$ and an important part $(23.2 \%)$ chose the submerged tunnel. From a grouping of the answers to an open question on not using the submerged tunnel, $51 \%$ claimed that the submerged tunnel will not be useful for their transport, $26.6 \%$ would avoid it because of the toll, $15.4 \%$ thought that it 
would not solve the traffic problems of the city or are opposed to its construction and a part of the participants $(6.5 \%)$ thought that the submerged tunnel will not be safe and expressed fear.

After that, the participants evaluated the impact the submerged tunnel would have on an environmental, traffic and urban level. As seen in Fig. 2, in the section of questions that refer to the impact on traffic, the participants view the contribution of the submerged tunnel as positive, as there is a tendency to see small or big improvement in most issues. On the contrary, in the environmental impact section, they view the artery skeptically, as they estimate that there will be a general deterioration in the environmental conditions of the city. Taking into consideration the section of impacts, we form the opinion that the citizens of Thessaloniki are aware of the environmental problems that will arise from the construction of the TST. Foremost among them, the environmental depreciation of the Thermaikos Gulf, followed by the reduction of the urban green spaces, the rise in the level of air pollution and noise pollution and finally the reduction of energy benefit that will occur from the project. At this point, we can argue that despite the lack of information on the conditions and the impacts of the project, the citizens acknowledge the urban problems that will accumulate from such a major intervention on the urban space. Therefore, we can see that they agree with the specialized scientists and the active public groups that worked at high pressure against the construction of the TST. Nevertheless, a contradiction in the citizens' opinion emerges from the questionnaire. On the one hand, the citizens are not fully opposed to the project as it seems to solve daily problems they face with an inefficient public transport network and the necessity to use a privately owned vehicle. On the other hand, the same citizens are completely aware of the sustainability problems of the project and its consequences on the natural and urban environment.

Concerning the urban impact, the participants do not have a unified position, as they believe that some interventions of the submerged tunnel will improve and others will worsen the city image. The traffic problem of the city and the image of the old quay are the two things most participants (62.3\% and $64.1 \%$, respectively) believe will benefit from the completion of this great

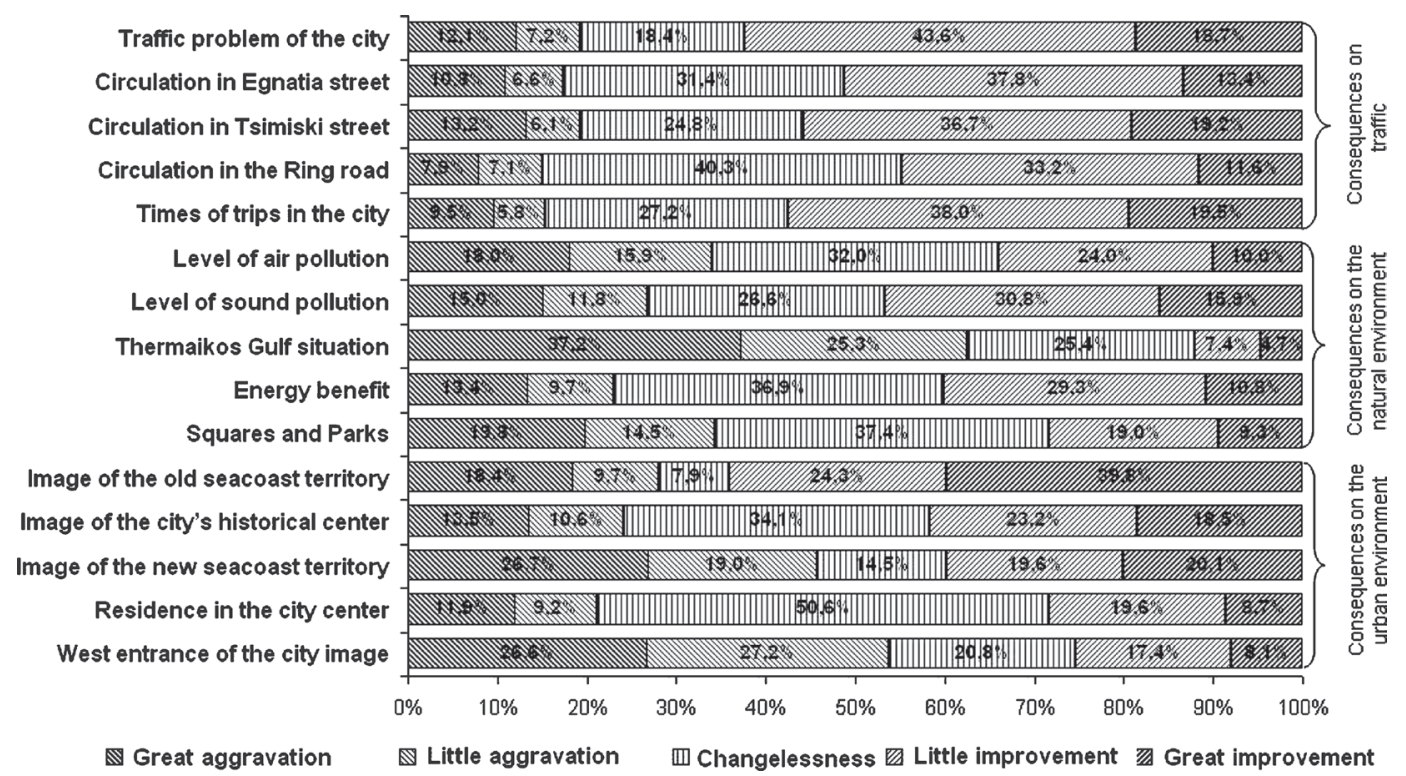

Figure 2: Views on the impact of the TST. 
project. On the contrary, the image of the western entrance of the city, the state of the Thermaikos gulf and the image of the new quay are the things most participants $(62.5 \%, 53.8 \%$ and $45.7 \%$, respectively) believe will suffer from the construction of the submerged tunnel. A more complete image of the participants' opinion on the impact of the submerged tunnel on the city of Thessaloniki is shown in Fig. 2.

\subsection{Areas of residence, transportation means and the submerged tunnel}

Through statistic process and the combination of some variants of the questionnaire, we found that those questioned on the transport from east to west or vice versa choose their route based on the area they reside in. Residents of the eastern suburbs would choose the submerged tunnel by $27.9 \%$, while the residents of the eastern districts, who would choose it by $18 \%$, appear to be more apprehensive. Furthermore, an important part of the residents of the center and the western districts, $26.7 \%$ and $25 \%$, respectively, would use the submerged tunnel. On the other hand, the ring road is the main artery for almost all areas of the city, as it is preferred by most residents of all areas, with the exception of those who reside in the center. It is worth noting that the residents of the suburbs (eastern and western) and to a lesser degree those in the western districts avoid transports through the city center, while a large percentage $(35.1 \%)$ of the residents in the eastern districts prefer to pass through it. A more complete image of the participants' choices concerning the route they would follow for their eastern or western transports, depending on their area of residency, can be seen in Fig. 3.

Considering the means of transportation and the route followed as parameters (passing through the main streets of the city, bypass via the ring road, use of the submerged tunnel), we notice that vehicle users mostly choose the ring road (56.3\%) - avoiding the center, as only $18.5 \%$ would choose it - while $25.2 \%$ would choose the submerged tunnel.

Considering the area of residence and the mobility from east to west or vice versa as parameters, we notice that the residents of the western and eastern suburbs ( $85.4 \%$ and $79.1 \%$, respectively), in contrast to the residents of the center, travel more often. To be exact, the reasons for transport from east to west and vice versa differ, depending on the area of residency, and it is found that the residents of the eastern districts travel to the west mainly for business reasons, while the residents of the western districts travel to the east for recreational and entertainment reasons.

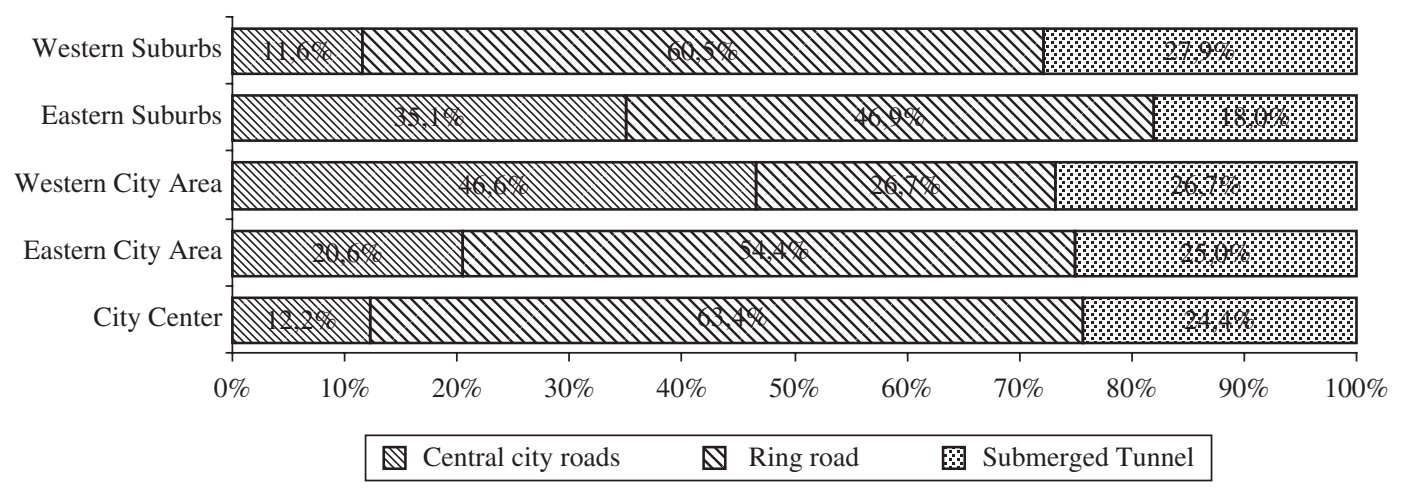

Figure 3: The participants' selected route for moving from east to west or vice versa, depending on the area of residence. 
In addition, significant differences appear in the evaluation of the submerged tunnel's impact depending on the participants' area of residency. So, residents of the western suburbs are more apprehensive as on almost every issue they predict deterioration because of its construction. The same image emerges from the residents of the center, with the exception of the questions on noise and the image of the old quay, where they predict the improvement of the current situation, which is mostly related with turning Nikis Avenue into a pedestrian zone. Residents of the eastern suburbs and the western districts appear more optimistic because on most questions they predict the improvement of the current situation with the construction of the submerged tunnel. How the participants evaluate the impact of the submerged tunnel is connected with the area they reside in. So, the tunnel in question would be selected mostly by the residents of the eastern suburbs and the western districts, as opposed to the residents of the western suburbs who have a negative opinion on the submerged tunnel's impact.

\subsection{Modern cultural models and dynamics of search for city transportation alternatives}

If we correlate the participants' sex with the intent to use the submerged tunnel (Fig. 4) and with their evaluation of its impact, not only do we see no differences between men and women but we also notice an extraordinary consistency in their answers. Men and women have the same percentages of intent to use the submerged tunnel and they evaluate its impact in the same way. In our opinion, this common behavior depicts that both sexes appear to agree when it comes to common problems of the city and concerns about transportation within it. This draws attention to equal participation of the two sexes in urban life and mobility. We could also make the assumption that both men and women of Thessaloniki adopt the model of modern mobility. We have already seen that the main means of transportation is the private car and this applies to both the men and the women of our sample. Combining this conclusion with the previous one whereby men and women tend to adopt common practices of transportation, we talked about the 'modern' cultural patterns of transportation, meaning the use of the private car especially by women. The increase in the percentage of female users of private cars, which enhances the symbolic image of the emancipated woman, is a relatively recent reality in Greece. On our part, as researchers, this notion of 'modern cultural pattern' is not approved but it serves as a comparative tool to show the difference in the social profile of the female sex in relation to the past. Modern women have a distinctive geographical mobility, thanks to the private

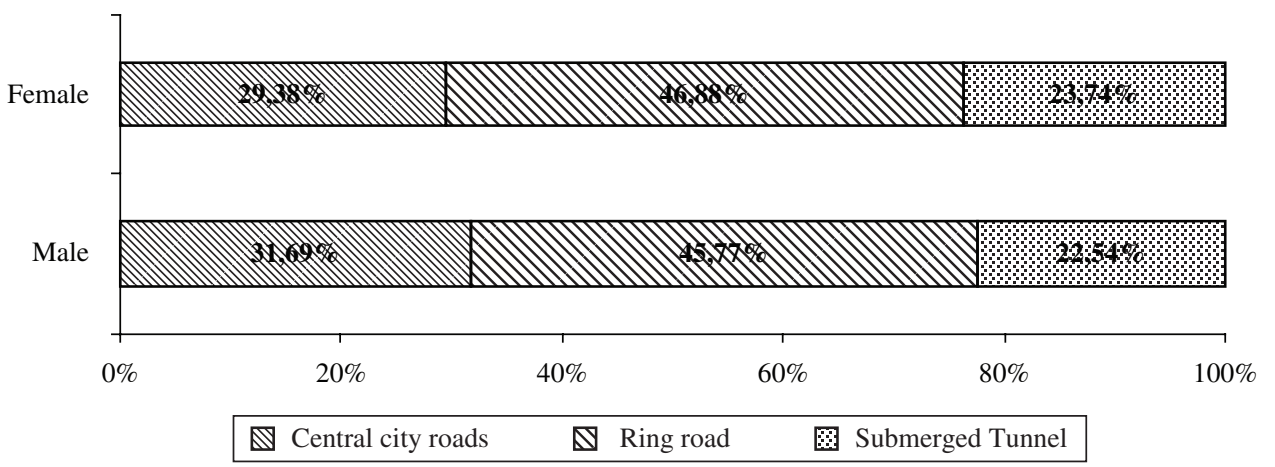

Figure 4: The participants' selected route for moving from east to west or vice versa, in relation to their sex. 
car, but they also come up against the same problems of traffic in the city as men do and respond in exactly the same way men do. In our opinion, the phenomenon of suburbanization is directly linked with this reality. The extensive use of the privately owned vehicle downgrades the sustainability of the city and stresses the prominent necessity, not so much, for the support of alternative routes for transport, as might be the TST, but the need for alternative public means of transport, such as metro, bus, sea transport, bicycle, etc.

As for the intent to use the submerged tunnel in relation to age, as is shown in Fig. 5, a significant portion of those belonging to the young age group (5-29 years old) would choose the submerged tunnel (larger than that for the other age groups), but they would mainly choose the city center and secondly the ring road. A majority of those in the middle age group (30-44 years old) prefer the ring road, while the rest are divided between the submerged tunnel and the center. The majority of those in the older age group (45+ years old) seem to avoid the submerged tunnel (as only $15.9 \%$ would chose it) and prefer taking the ring road. So we could say that younger ages tend to adopt 'alternative' transportation choices more easily, although in our sample this age group has the lowest percentage of transportation with a privately owned vehicle $(30.1 \%)$ in reference to the other age groups. This could be interpreted as a result of not experiencing the problem of traffic in the city in the same way the other age groups do. On the contrary, older age groups avoid the submerged tunnel (as only 15.9\% would choose it), a fact that can be interpreted as an illustration of their realism and pessimism. We could also explain this choice of the older ages as a result of the use of a privately owned vehicle by $63.5 \%$ of this age group.

Finally, how the participants evaluate the impact is related to their intent, or lack of, to use the submerged tunnel (Fig. 3). Therefore, as we see in Fig. 6, those who would choose the city center, face on the submerged tunnel with reserve and recognize negative impacts on almost all sections. On the contrary, in the section of traffic impacts, they adopt a positive attitude and recognize the positive contribution of the project.

As we can deduce from Fig. 7, a similar attitude is also adopted by those who would choose the ring road, though slightly more neutral as far as the impacts on both the urban and environmental sections are concerned and more positive as far as the impacts on the traffic section are concerned.

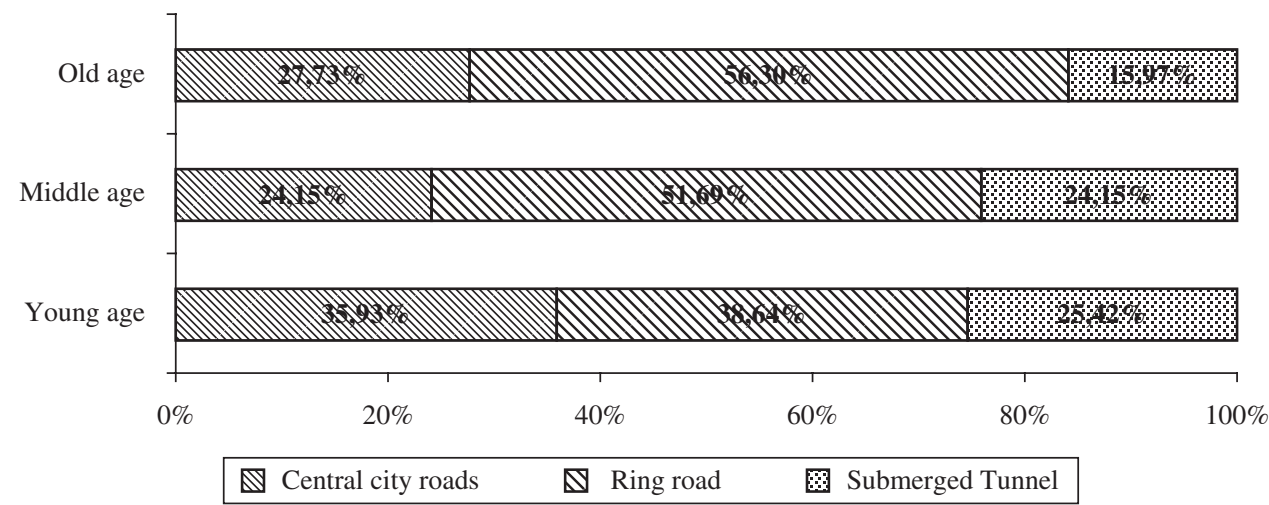

Figure 5: The participants' selected route for moving from east to west or vice versa, in relation to their age. 


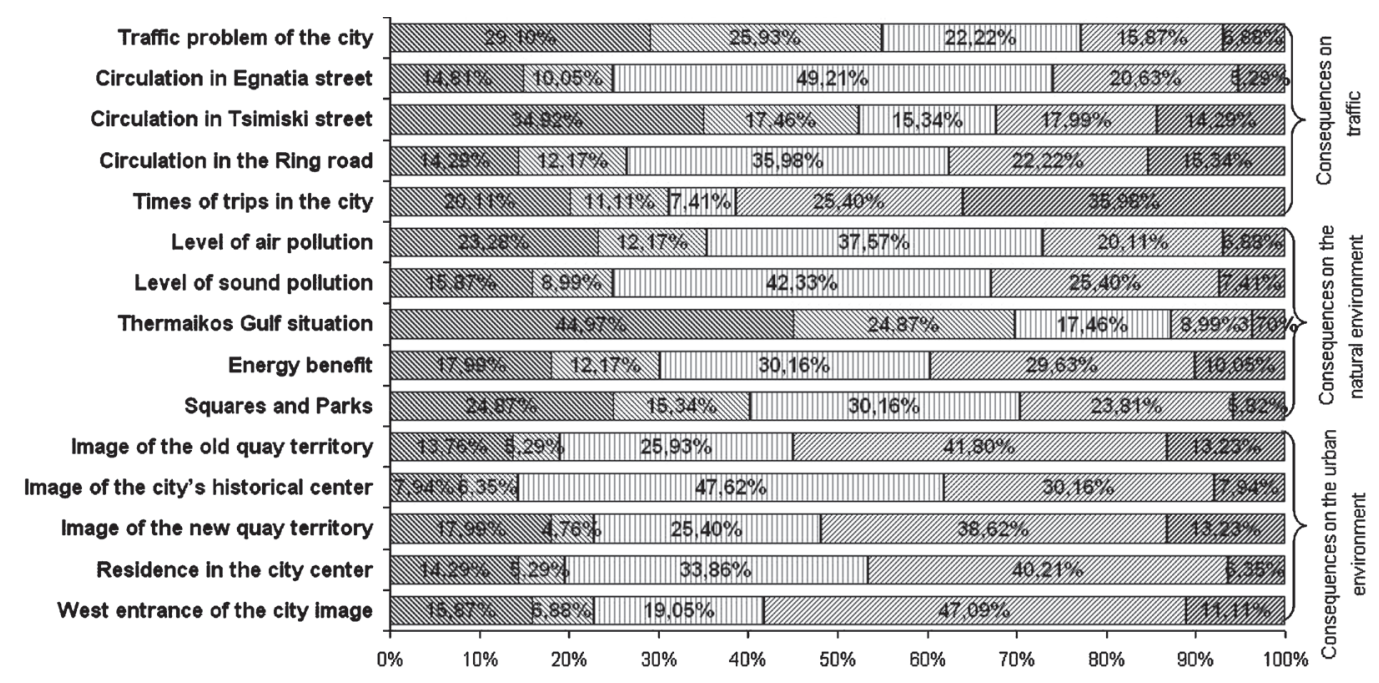

$\mathbb{B}$ Great aggravation $\mathbb{Q}$ Little aggravation $\quad$ Changelessness $\quad$ Little improvement Great improvement

Figure 6: Views on the impact of the TST in relation to the intent of using the city center.

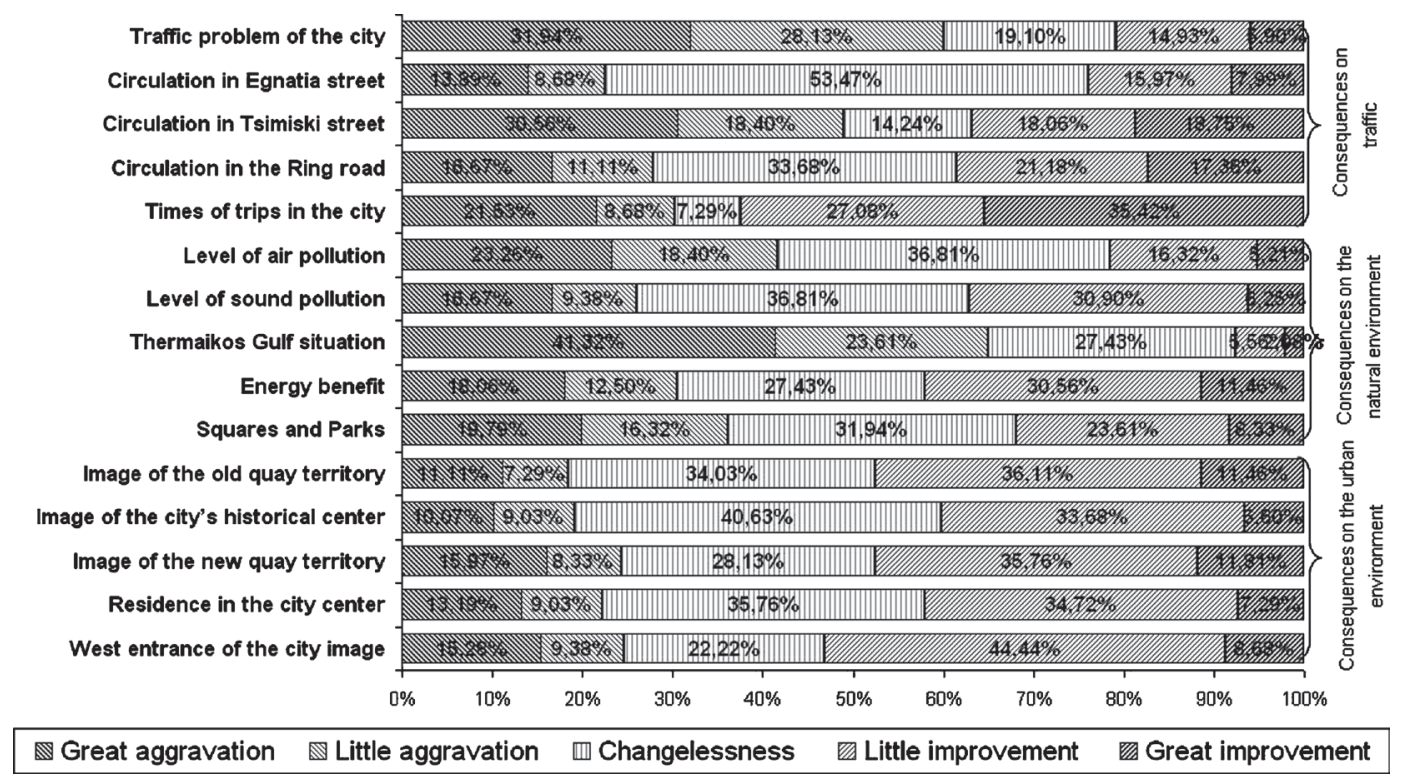

Figure 7: Views on the impact of the TST in relation to the intent of using the ring road.

On the other hand, as can be seen in Fig. 8, a controversial attitude seems to be adopted by those who would choose the submerged tunnel, as they see positive impacts in all the sections with significantly high percentages. Especially in the section on traffic impacts, we can observe that they assume that the TST project will result in important improvements in all the substantive sections and what is very important is the large percentages of improvement (almost 50\%). 


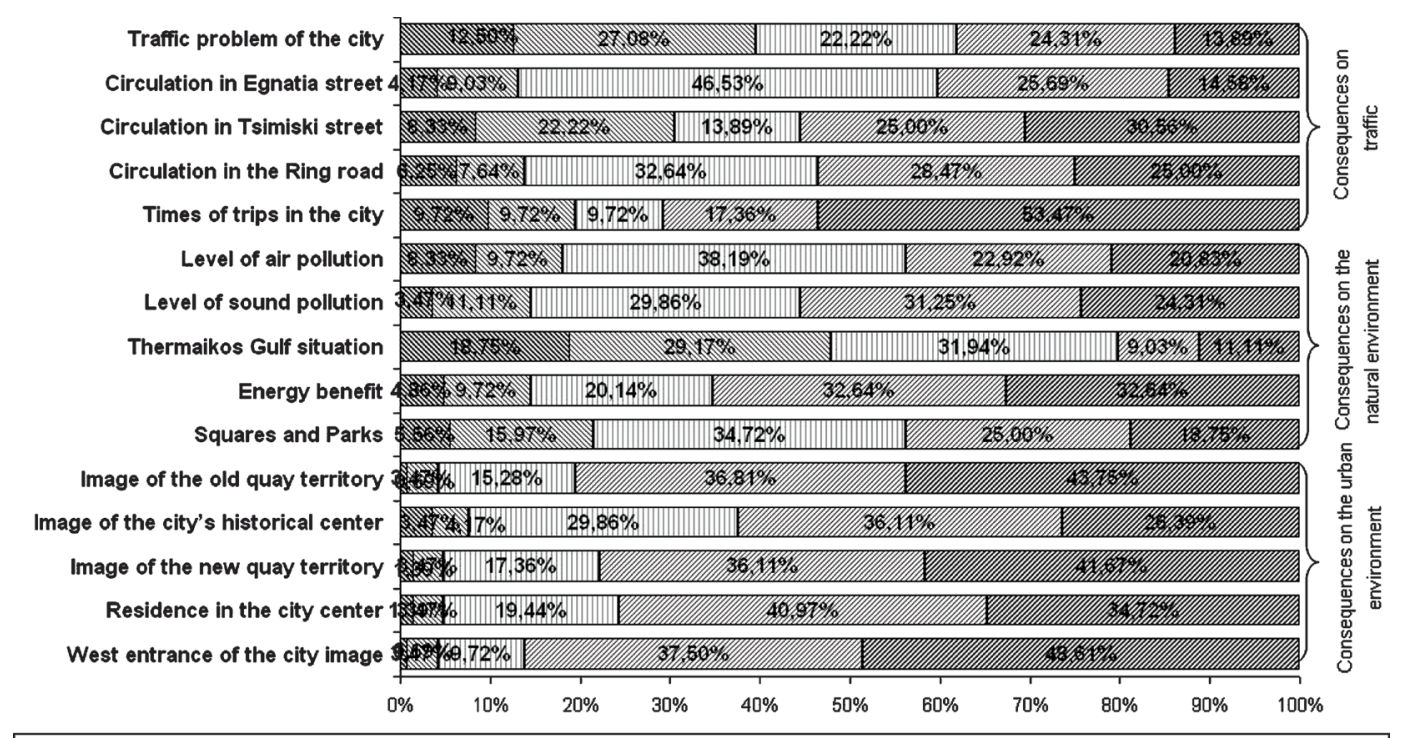

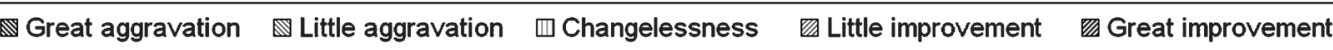

Figure 8: Views on the impact of the TST in relation to the intent of its use.

It would be reasonable to correlate the way the participants evaluate the impacts of the submerged tunnel with their intention to use it. As a result, those who choose to approve the project and intend to use it show a positive attitude as they accept and trust it for their transfer. On the contrary, those who use the ring road and to a bigger extent the users of the city center originally reject the project as they avoid using it. Therefore, it is only reasonable that they predict negative consequences from this project. Nevertheless, what is impressive is that although they have a negative attitude towards the project, they still recognize the possible positive contribution it might have on the traffic sector.

\section{CONCLUSIONS}

By analyzing the citizens' opinions about the consequences of the TST on the city of Thessaloniki, we can draw some basic conclusions that are related with basic concepts of spatial planning and major developmental projects. The submerged tunnel is viewed in contradicting ways as the evaluation of the citizens pinpoints the positive and the negative sides of it (see Fig. 2). This contradiction lies in the fact that even though they ascertain that the project does not meet the precondition of sustainable development, they simultaneously recognize that it will have a positive impact on the traffic. The reason for the aforementioned contradiction is that citizens have been poorly informed, have hardly been asked to participate in the decision-making process and have therefore been constrained in using their own privately owned vehicle due to the lack of an effective public transportation system. The citizens of Thessaloniki see the submerged tunnel as a project of localized intervention, while we notice the participants' high preference for the use of the ring road, as it serves almost all areas of the city, as opposed to the TST that only serves part of it.

Also, through the research we can see the distrust of the local community of major Thessaloniki, a fact that has its roots in the lack of information and attests the absence of participatory processes which every spatial intervention requires. Besides, the greatest advantage of participatory planning is the wide social acceptance of such important spatial interventions. 
It is now unquestionable that the tendencies of metropolization and urban diffusion of Thessaloniki are closely related to the boom of mobility and the emergence of new areas of activity, like recreational and commercial centers in the east (IKEA and COSMOS) that attract users from all regional cities of Central Macedonia and beyond. Of course, the residents of the city and its wider region are not indifferent to this attraction. Furthermore, Thessaloniki seems to connect the American and the European model of city development that is diffused but insists on the importance of the traditional city center, and this is portrayed in the tendency to approach the historical center. The citizens' answers show that they are aware of the problems of the city, they participate in the city's social life with an intense mobility, they adopt a modern suburban model of living and they trust the existing and - at least so far - efficient solutions of transportation (ring road).

\section{REFERENCES}

[1] Gospodini, A. \& Beriatos, I., Introduction: Transformations of urban landscapes in the conditions of globalization, cities competition and postmodern societies. New Urban Landscapes and the Greek City, eds A. Gospodini \& I. Beriatos, Kritiki: Athens, pp. 15-23, 2006.

[2] Albrechts, Thoughts about planning. Aeichoros, 1(1), pp. 196-207, 2002.

[3] Remy, J., Voye, L. \& Servais, E., Produire ou reproduire? I. Conflits et transaction sociale, Vie Ouvrière: Bruxelles, 1978.

[4] Rapoport, A., Anonymous Architecture, Architectural Subjects: Athens, 1976.

[5] Aravantinos, A., Urban Planning for the Sustainable Development of the Urban Space, Symmetria: Athens, pp. 403-470, 1997.

[6] Coccosis, C. Urban planning for sustainable cities; The perspective of the environmental planning for the sustainable development. In the honorary volume for Professor Athanasios Aravantinos, City and Space from the 20th to the 21st Century, Athens, National Technical University of Athens, Greek Association of Urban and Regional Planners, pp. 233-242, 2004.

[7] http://ypothalassia.wordpress.com/

[8] Kafkalas, G., Labrianidis, L. \& Papamichos N., The great adventure of great projects. Makedonia Newspaper, published 4-2-2007, http://estia.arch.auth.gr/news3.htm.

[9] Park, R.E., Human Communities: The City and Human Ecology, Free Press: New York, 1952.

[10] Giddens, A., Sociology, Gutenberg: Athens, 2002.

[11] Remy, J., Sociologie urbaine et rurale: L'espace et l'agir, L'Harmattan: Paris, 1998.

[12] Remy, J., Métropolisation et diffusion de l'urbain. les ambiguittés de la mobilité. Les territoires de la mobilité, eds M. Bonnet \& D. Desjeux, Presses Universitaires de France: Paris, pp. 171-188, 2000.

[13] Getimis, P., The importance of new forms of governance in empowering the international role of Athens-Attica in the context of the new spatial competition of extended Europe. In the honorary volume for Professor Athanasios Aravantinos, City and Space from the 20th to the 21st Century, Athens, National Technical University of Athens, Greek Association of Urban and Regional Planners, pp. 147-165, 2004.

[14] Karaletsou, K. \& Papageorgiou, R., Social and Cultural Views on Urban Space, Tutorial Notes, Aristotle University of Thessaloniki, School of Architecture, University Press, Thessaloniki, 1998.

[15] Tzitzikostas, A., Organization and operation of the urban environment. Epikentra, (4), Athens, 2005.

[16] Hellenic Institute of Transportation Engineers, Views of HITE on Thessaloniki's Transportation System, 2005. 